Rabaska

Revue d'ethnologie de l'Amérique française

\title{
ARSENAULT, GEORGES. Noël en Acadie. Tracadie-Sheila, La \\ Grande Marée, 2005, 164 p. ISBN 2-921722-67-4
}

\section{Noëlla Richard}

Volume 4, 2006

URI : https://id.erudit.org/iderudit/201774ar

DOI : https://doi.org/10.7202/201774ar

Aller au sommaire du numéro

Éditeur(s)

Société québécoise d'ethnologie

ISSN

1703-7433 (imprimé)

1916-7350 (numérique)

Découvrir la revue

Citer ce compte rendu

Richard, N. (2006). Compte rendu de [ARSENAULT, GEORGES. Noël en Acadie. Tracadie-Sheila, La Grande Marée, 2005, 164 p. ISBN 2-921722-67-4]. Rabaska, 4,

143-144. https://doi.org/10.7202/201774ar

Ce document est protégé par la loi sur le droit d'auteur. L'utilisation des services d’Érudit (y compris la reproduction) est assujettie à sa politique d'utilisation que vous pouvez consulter en ligne.

https://apropos.erudit.org/fr/usagers/politique-dutilisation/
Cet article est diffusé et préservé par Érudit.

Érudit est un consortium interuniversitaire sans but lucratif composé de l’Université de Montréal, l’Université Laval et l’Université du Québec à Montréal. Il a pour mission la promotion et la valorisation de la recherche. https://www.erudit.org/fr/ 


\section{Comptes rendus}

Arsenault, Georges. Noël en Acadie. Tracadie-Sheila, La Grande Marée, 2005, 164 p. ISBN 2-921722-67-4.

Diplômé d'une maîtrise en Arts et traditions populaires de l'Université Laval, Georges Arsenault est un auteur qui se spécialise dans le travail de terrain. En plus de sa collection considérable d'enquêtes déposée au Centre d'études acadiennes de l'Université de Moncton et aux.Archives de folklore de l'Université Laval, ce chercheur a fait bon nombre d'entrevues au cours de ses quinze ans de travail comme animateur à l'émission du matin à la radio de Radio-Canada, édition Île-du-Prince-Édouard. Auteur prolifique, il a touché un peu à tout, allant des complaintes (Complaintes acadiennes de l'Île-du-Prince-Édouard, 1980) aux fêtes d'antan (Courir la chandeleur, 1982). Ses enquêtes lui ont permis de rencontrer maints conteurs et conteuses, ce qui mena à la publication de Par un dimanche au soir : Léah Maddix, chanteuse et conteuse acadienne (1993) et Contes, légendes et chansons de l'̂̂le-du-Prince-Édouard (1998). Il a écrit l'histoire de sa région natale, Le Guide historique de la région Évangéline (1994), et a reçu le prix Champlain ainsi que le prix France-Acadie pour son ouvrage Les Acadiens de l'lle : 1720-1980 (1987).

Cette fois, dans Noël en Acadie, M. Arsenault nous livre un nouveau regard : au lieu d'examiner les anciennes coutumes acadiennes, il considère plutôt une fête populaire célébrée un peu partout dans le monde et son effet sur la communauté acadienne. Bien que Noël soit une fête chrétienne, toutes les recherches portent à croire qu'elle se limitait à une simple célébration liturgique lors de l'arrivée des premiers colons en Acadie ou même dans la France des XVII ${ }^{-}$- XVIII ${ }^{e}$ siècles. Il semble même que c'était une journée de travail comme les autres. Il n'y a pas de mention de saint Nicolas ni d'arbres de Noël ni de cadeaux pour les enfants dans les œuvres consultées. Ce n'est qu'au XIX ${ }^{\mathrm{e}}$ siècle que l'on commence à trouver des mentions de rituels plutôt modernes. M. Arsenault examine ici l'insertion graduelle de ces coutumes païennes dans la société acadienne et son effet sur la culture.

L'auteur a tenté de toucher à tous les aspects de la fête : les préparatifs, les célébrations liturgiques, le réveillon, la cuisine, Santa Claus et saint Nicolas, l'arbre de Noël, les concerts de Noël, ainsi que quelques traditions 
très spécifiques aux Acadiens, tel que le naulet, un petit biscuit en forme d'homme donné à un enfant par sa marraine et son parrain le matin de Noël ou au jour de l'an. L'auteur nous démontre aussi comment certaines traditions étaient difficiles à apprivoiser alors que d'autres se sont intégrées dans la société sans qu'on le réalise.

M. Arsenault puise dans plusieurs sources pour sa démonstration. Dans presque tous les chapitres, il y a une série de témoignages de gens d'un peu partout en Acadie, ce qui permet au lecteur d'identifier les similarités et les différences des traditions selon les régions. Il a aussi dépouillé les journaux français de l'époque (Le Moniteur acadien, L'Impartial et L'Évangéline), des annonces parues à la fin du XIX $\mathrm{XI}^{\mathrm{e}}$ siècle. De nombreux dessins et photos, incluant quelques-unes de la collection privée de l'auteur, viennent appuyer les propos. De même, des cartes géographiques représentent la plupart des régions acadiennes en Amérique du Nord. Bien qu'elles permettent au lecteur de situer un peu les Acadiens dans les provinces de l'Atlantique et le Québec, elles sont distribuées un peu pêle-mêle, et hors propos. Il aurait peut-être été bien de les placer au début du volume afin que le lecteur puisse s'y référer au besoin. Également, la population des régions indiquées date du Recensement de 1976 ; des chiffres un peu plus récents auraient été appréciés. Enfin, il aurait été utile d'ajouter le glossaire (p. 161) et la liste des cartes (p. 164) à la table des matières. Pour faciliter la compréhension du vocabulaire acadien, des notes infrapaginales auraient éliminé toute confusion possible.

Chacun trouvera son compte dans ce livre destiné au grand public, car c'est un excellent point de départ pour quiconque youdrait faire une recherche sur les coutumes de sa propre famille. Ainsi, l'auteur a fait un grand cadeau de Noël à l'Acadie, aux chercheurs et aux amateurs de folklore.

NólLla Richard Mont-Carmel, île-du-Prince-Édouard 